\title{
Accuracy estimation of the IfE gravimeters Micro-g LaCoste gPhone-98 and ZLS Burris Gravity Meter B-64
}

\author{
Manuel Schilling Olga Gitlein
}

Published in: Rizos C., Willis P. (eds) IAG 150 Years. International Association of Geodesy Symposia, vol. 143, pp. 249-256. Springer, Cham. DOI:10.1007/1345_2015_29, 2015.

Presently, modern spring gravimeters are the most flexible, technically simple, and comparatively cheap solution for recordings over extended time periods in contrast to superconducting gravimeters. We investigate the accuracy of the state-of-the-art spring gravimeters Micro-g LaCoste gPhone-98 and ZLS Burris Gravity Meter B-64 of the Institut für Erdmessung (IfE). With both instruments gravity was recorded for periods of several months at five stations with high and low microseismic noise. Simultaneous measurements with both instruments as well as the parallel recording of the ZLS Burris gravimeter with the GWR Instruments Observatory Superconducting Gravimeter OSG-054 in Onsala (Sweden) are investigated. Tidal analysis is used to assess the quality of the time series. Diurnal and semi-diurnal amplitude factors agree at the level of $1 \%$ and better from recordings of Burris and OSG gravimeters in Onsala.

In addition to gravity recordings a number of calibration experiments were carried out to test the long-term stability of the meters. The linear calibration factor of both gravimeters is stable to $3 \times 10^{-4}$. The drift of the gPhone-98 decreased over time and is currently reduced with a linear factor of $\approx 90 \mathrm{~nm} / \mathrm{s}^{2}$ per day. The instrumental drift of Burris B-64 on the other hand can currently not be reduced with a linear factor.

Schlagworte: Relative Gravimetry, gPhone, ZLS Burris, instrumental accuracy, tidal analysis

\section{Introduction}

Modern spring-based gravimeters are a versatile tool in gravimetry. The possible applications include Earth tide recordings, monitoring of geophysical phenomena, and microgravimetric measurements supporting absolute gravimetry. Especially when recording gravity these instruments are limited by the continuous variation of spring tension, which causes a drift effect. Gravity changes due to Earth tides can reach more than $2000 \mathrm{~nm} / \mathrm{s}^{2}$. Other changes of gravity are orders of magnitude smaller, e.g. changes in the groundwater can be in the order of a few to some $10 \mathrm{~nm} / \mathrm{s}^{2}$ over a few days to weeks. These small signals might not be revealed due to instrumental drift. Therefore, it is necessary that the instrumental drift is easy to model, preferably linear, and stable over time. All metal alloy- or quarz-spring based gravimeters are affected by instrumental drift, independent of their respective design. For example Timmen and Gitlein (2004) reported a drift of $\approx 2.7 \mu \mathrm{m} / \mathrm{s}^{2}$ per day for the Scintrex CG3-4492, which uses a vertical quartz spring.

This work focuses on two instruments employed by the IfE. The gPhone-98 is in use for two years and the Burris B-64 for one year by now. The gPhone has been in use almost continuously at different stations. We present Earth tide recordings made at four stations which have been made in preparation of a future geophysical project and to examine the instrument. Other observations were used as a reference in the development of recording atomic gravimeters in Hannover and Berlin. The Burris has been recording Earth tides at three stations. 
The stations visited have very different characteristics, e.g. concerning the influence of nearby waterbodies and man made microseisms. The measurements were performed in Onsala, Hamburg, Hannover, Ruthe, and Clausthal (Figure 11). The stations Hannover (Leibniz Universität Hannover) and Clausthal (Clausthal University of Technology), both with a history of gravity measurements dating back to 1986, are briefly described by Timmen (2010). The gravimetry laboratory in Hannover is located in an university Building next to a parking lot, a 20 story building and tram lines near by. The laboratory is equipped with three dedicated pillars for absolute and relative gravimeters. Ruthe is located $20 \mathrm{~km}$ south of Hannover in a rural area and has four pillars in a climate controlled container. The station in Hamburg is located in a residential district close to the Elbe river with water level changes of 3-4 m over $12 \mathrm{~h}$ due to the direct connection to the North Sea. The measurements were conducted in the basement of an empty building. The aforementioned three stations are located on glacial sediments. Clausthal is located in the Harz mountains and the pillar is directly connected to bedrock. This station is characterized by low natural and man made ground noise. Onsala, Sweden, is located $40 \mathrm{~km}$ south of Gothenburg at the Onsala Space Observatory, Chalmers University Gothenburg (Scherneck, 2008) close to the Kattegat coast. The measurements were performed in a builduing equipped with a superconducting gravimeter on a pillar connected to bedrock.

\section{Characterization of the instruments}

The gravimeters gPhone- 98 and Burris B-64 operate by the same basic principle. Both instruments use the LaCoste \& Romberg design for spring based gravimeters and a metal alloy spring. The relationship between LaCoste \& Romberg Model D and G instruments and the Burris Gravimeter is obvious by its appearance (LaCoste \& Romberg, 2004, ZLS Corporation, 2011), and the gPhone is based on the LaCoste \& Romberg Model G gravimeter (Micro-g LaCoste, 2008).

The instruments were placed in styrofoam boxes to reduce the effects of room temperature variations at all stations. These variations are likely to affect the tilt of the instruments. In case of the gPhone the electronic levels are recorded along with gravity. Inside the box the daily variation of the temperature is typically below $0.5^{\circ} \mathrm{C}$. However, over the duration of several weeks the mean temperature changed slowly by $2^{\circ} \mathrm{C}$ and more at stations without

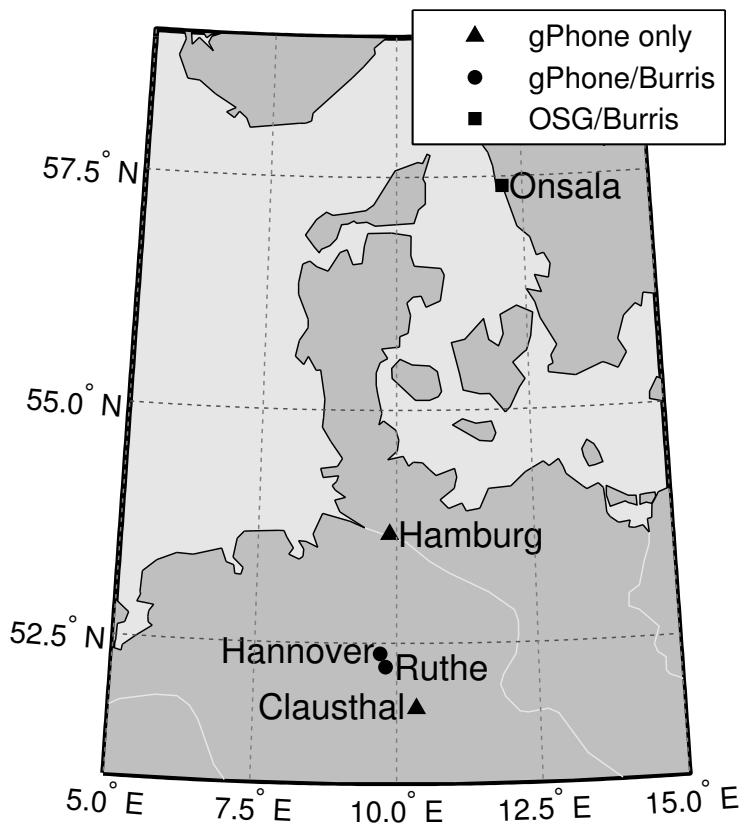

Figure 1: Stations and co-locations of instruments in Germany and Sweden

climate control.

gPhone The gPhone is specifically designed for gravity recordings. The sensor offers an electronic feedback range of $\pm 500 \mu \mathrm{m} / \mathrm{s}^{2}$, a resolution of $1 \mathrm{~nm} / \mathrm{s}^{2}$, and is housed in a double oven for temperature stabilization (Micro-g LaCoste, 2008). Reranging the sensor within its $7 \mathrm{~cm} / \mathrm{s}^{2}$ range and clamping is done with the software gMonitor (Version 1.09.10.12) installed on a Laptop, which records data and controls the instrument. The sensor is connected to the electronic box, which houses an uninterruptible power supply and a timing module (rubidium clock). A GPS antenna can be connected to the timing module as well. gMonitor records a variety of instrumental and environmental data in addition to gravity, which include the electronic levels of the sensor, ambient and sensor air pressure and temperature. The data recorded at $1 \mathrm{~Hz}$ is unfiltered. gMonitor also records $300 \mathrm{~s}$ filtered data, which is not used in this paper.

Burris The Burris gravimeter is used for point-wise measurements and the recording of time series. The range of the electronic feedback system is $\pm 250 \mu \mathrm{m} / \mathrm{s}^{2}$. The analog gravity output is filtered with a low pass filter, which adds a $0.6 \mathrm{~s}$ phase delay (ZLS Corporation, 2011). The range of the instrument is $7 \mathrm{~cm} / \mathrm{s}^{2}$ and the reranging of the feedback system has to be done manually. The 
Burris B-64 has a non calibrated micrometer screw for this purpose. Gravity differences exceeding the range of the electronic feedback system have to be divided into smaller differences with the Burris B-64. A calibrated screw has calibration points at a $500 \mu \mathrm{m} / \mathrm{s}^{2}$ interval and allows the measurement of gravity differences exceeding $500 \mu \mathrm{m} / \mathrm{s}^{2}$ in one step. Jentzsch (2008) reported the precision of the calibration points to be $\pm 150 \mathrm{~nm} / \mathrm{s}^{2}$ for the Burris B-25.

The Burris is controlled with a handheld computer running Palm OS 9 and the UltraGrav software. The handheld computer is connected with Bluetooth or a cable to the gravimeter. UltraGrav is capable of continuous gravity recording with a user defined sample rate and digital filter as well as network measurements. A level correction is calculated and recorded using the electronic levels of the instrument. The measurements in this study were recorded with the software FSUGrav provided by the company Gravity Consult. The software is installed on a standard Laptop connected with Bluetooth to the gravimeter. In addition to gravity readings the software records ambient air pressure with a digital barometer. The electronic levels or a level correction is not recorded by FSUGrav. The time is obtained using either a GPS time receiver or a connection to a NTP server. FSUGrav records gravity and air pressure data in a fixed $10 \mathrm{~s}$ interval. The gravity recordings are filtered using a $600 \mathrm{~s}$ zero-phase filter, which allows no further adjustments.

Calibration The gravimeters are regularly calibrated on the vertical calibration system Hannover (Timmen, 2010), which offers, among others, a $160 \mu \mathrm{m} / \mathrm{s}^{2}$ gravity difference between the 1st and 17th floor of an university building. The electronic levels of the gravimeters were calibrated and the linear calibration factors were determined prior to all deployments to a different station. The results are listed in Table 1 and the linear term is time stable for both gravimeters at the level of $3 \times 10^{-4}$. For a signal with an amplitude of $3000 \mathrm{~nm} / \mathrm{s}^{2}$ the effect of omitting the differences in the linear calibration factors is below $1 \mathrm{~nm} / \mathrm{s}^{2}$. A quadratic term has been determined for the Burris during some of the calibrations and was found to be below $\pm 0.5 \times 10^{-9}$, which agrees with the measurements of Jentzsch (2008).

Instrumental Drift The instrumental drift for the different time series is estimated by a piecewise linear approximation of 7 day intervals. The mean linear drift factors are listed in Table 2. After a recording of the
Table 1: Linear calibration factors. $\delta$ is the difference to the mean linear calibration factor.

\begin{tabular}{|c|c|c|c|c|c|}
\hline \multicolumn{3}{|c|}{ gPhone-98 } & \multicolumn{3}{|c|}{ Burris B-64 } \\
\hline Date & $\begin{array}{l}\text { linear } \\
\text { factor }\end{array}$ & $\begin{array}{l}\delta \\
{\left[10^{-3}\right]}\end{array}$ & Date & $\begin{array}{l}\text { linear } \\
\text { factor }\end{array}$ & $\begin{array}{l}\delta \\
{\left[10^{-3}\right]}\end{array}$ \\
\hline $12 / 2011$ & 1.00240 & 0.015 & $04 / 2012$ & 0.99974 & -0.354 \\
\hline $04 / 2012$ & 1.00206 & 0.366 & $04 / 2012$ & 0.99953 & -0.138 \\
\hline $08 / 2012$ & 1.00247 & -0.122 & $05 / 2012$ & 0.99944 & -0.059 \\
\hline \multirow[t]{6}{*}{$02 / 2013$} & 1.00268 & -0.259 & $09 / 2012$ & 0.99895 & 0.441 \\
\hline & & & $11 / 2012$ & 0.99937 & 0.042 \\
\hline & & & $01 / 2013$ & 0.99961 & -0.222 \\
\hline & & & $02 / 2013$ & 0.99963 & -0.237 \\
\hline & & & $05 / 2013$ & 0.99946 & -0.169 \\
\hline & & & $07 / 2013$ & 0.99870 & 0.692 \\
\hline mean & \multicolumn{2}{|c|}{$1.00242 \pm 0.00027$} & & \multicolumn{2}{|c|}{$0.99939 \pm 0.00033$} \\
\hline
\end{tabular}

Table 2: Overview of gravity time series. Drift is estimated by a sequence of linear fitted lines with a length of 7 days. The standard deviation $\sigma$ is estimated for the nummerical differentiated gravity residuals.

\begin{tabular}{|c|c|c|c|c|c|}
\hline & Location & $\begin{array}{l}\text { Start } \\
\mathrm{mm} / \mathrm{yy}\end{array}$ & Days & $\begin{array}{l}\text { Drift } \\
{\left[\mathrm{nm} / \mathrm{s}^{2} / \text { day }\right]}\end{array}$ & $\begin{array}{l}\sigma\left[\mathrm{nm} / \mathrm{s}^{2}\right] \\
1 \mathrm{~s}\end{array}$ \\
\hline \multirow{5}{*}{  } & Hannover & $10 / 11$ & 55 & $191.2 \pm 12.5$ & 730.9 \\
\hline & Hamburg & $01 / 12$ & 84 & $126.2 \pm 4.6$ & 528.2 \\
\hline & Clausthal & $05 / 12$ & 98 & $117.1 \pm 2.6$ & 150.6 \\
\hline & Ruthe & $02 / 13$ & 152 & $93.9 \pm 1.8$ & 446.9 \\
\hline & Location & $\begin{array}{l}\text { Start } \\
\mathrm{mm} / \mathrm{yy}\end{array}$ & Days & $\begin{array}{l}\text { Drift } \\
{\left[\mathrm{nm} / \mathrm{s}^{2} / \text { day }\right]}\end{array}$ & $\begin{array}{l}\sigma\left[\mathrm{nm} / \mathrm{s}^{2}\right] \\
10 \mathrm{~s}\end{array}$ \\
\hline \multirow{5}{*}{ 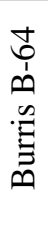 } & $\Omega$ & $06 / 12$ & 48 & $-209.4 \pm 61.2$ & 3.1 \\
\hline & & $07 / 12$ & 49 & $-155.4 \pm 39.2$ & 4.0 \\
\hline & Hannover & $09 / 12$ & 45 & $-177.4 \pm 15.0$ & 3.7 \\
\hline & Put & $03 / 13$ & 45 & $43.0 \pm 75.9$ & 3.6 \\
\hline & Kutne & $05 / 13$ & 21 & $-10.4 \pm 44.5$ & 3.7 \\
\hline
\end{tabular}

gPhone-98 is started the instrument shows a non linear behavior during the first $2-3$ weeks, hence the first two weeks are excluded from the determination of the drift. An example of gPhone gravity residuals is depicted in the black plot of Figure 2. However, after this initial run-in phase the drift seems to be linear. The instrumental drift of gPhone-98 is listed in the upper part of Table 2 . During the two years, the measurements for this study were recorded, the instrumental drift as well as its variation decreased. Currently, the drift is at $\approx 90 \mathrm{~nm} / \mathrm{s}^{2}$ per day. Riccardi et al. (2011) reported an instrumental drift at the level of $50 \mathrm{~nm} / \mathrm{s}^{2}$ per day for the gPhone-54 in a 300 day time series. The grey plot in Figure 2 shows an example of the gravity residuals of a Burris time series. The initial 


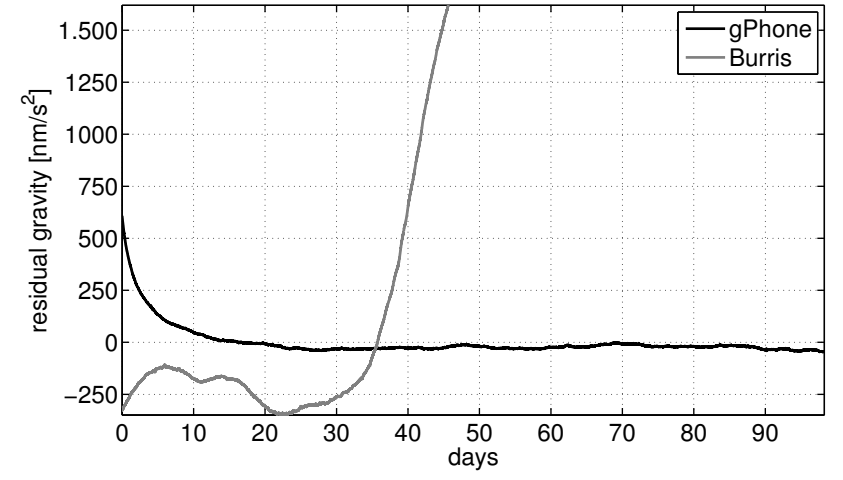

Figure 2: Example of residual gravity of gPhone-98 $\left(116.8 \mathrm{~nm} / \mathrm{s}^{2}\right.$ per day linear trend removed) and Burris B-64

run-in phase lasts a few hours but does not converge into a predictable behavior. The lower part of Table 2 shows that currently neither the drift nor its variation decrease over time when estimated by a piecewise linear approximation.

Additional investigations of Burris The influence of non gravitational air pressure changes on the Burris were tested in a pressure chamber. In a series of tests gravity was recorded while the air pressure was lowered and raised by $70 \mathrm{hPa}$. This variation can be encountered when measuring a gravity network which covers over $600 \mathrm{~m}$ in height. This resulted in a change of the measured gravity by $8-12 \mathrm{~nm} / \mathrm{s}^{2}$. A linear coefficient of $\approx 0.14 \mathrm{~nm} / \mathrm{s}^{2}$ per $\mathrm{hPa}$ has been found for the instrumental air pressure effect. The recordings of the Burris instrument were corrected for this effect. The gPhone was not tested in our pressure chamber due to the size of the instrument. According to the manufacturer the sensor is placed inside two pressure tight chambers. And, as opposed to the Burris, there are no mechanical elements (e.g. a measuring screw) reaching into the sensor chamber (Micro$\mathrm{g}$ LaCoste, 2008). The sensor air pressure is recorded and no correlation with ambient air pressure has been found. The sensor pressure of the gPhone- 98 decreases with $0.055 \mathrm{hPa} /$ day. This effect would be interpreted as a linear drift component to the overall instrumental drift.

The instrumental phase lag has been determined for the Burris using the step response method described in Richter and Wenzel (1991). The time lag was 3 seconds on average which results in a phase lag of $0.012^{\circ}$ for diurnal and $0.024^{\circ}$ for semi diurnal tidal waves. This phase lag is considered in the tidal analysis in section 4.

The Burris has been used along with the Scintrex CG3-
4492 (Timmen and Gitlein, 2004) in a small scale gravity network consisting of 13 points. Over a period of 3.5 days 160 connections were measured with the Burris and 125 with the CG3 using the step method and hand transport with a maximum of 10 minutes time for transport. The CG3 achieved a standard deviation $43 \mathrm{~nm} / \mathrm{s}^{2}$ for a single gravity difference and $17 \mathrm{~nm} / \mathrm{s}^{2}$ as the mean standard deviation of the adjusted gravity values. The Burris achieved standard deviations of $23 \mathrm{~nm} / \mathrm{s}^{2}$ and $10 \mathrm{~nm} / \mathrm{s}^{2}$ respectively. This agrees with the results reported by Jiang et al. (2012) using the B-20 and B-25 in the relative gravimeter campaign associated with the ICAG 2009 at the BIPM, Paris.

\section{Comparison of instruments and stations}

The data of both instruments were processed in the same manner. Gravity changes due to Earth tides and polar motion were corrected. If not stated otherwise the synthetic tide model including ocean loading of Timmen and Wenzel (1995) was used. Additionally, time variable gravity changes due to atmospheric masses were reduced using a single admittance factor for each station. For the Burris the instrumental air pressure effect was accounted for by using the factor described in the previous section. Earthquakes, spikes, and steps have been removed using Tsoft (Van Camp and Vauterin, 2005). The data was calibrated using the factors listed in Table 1 . The level correction was applied for gPhone.

The quality of data depends on the gravimeters and the stations. We compare the data of the instruments and stations using the standard deviation of the numerically differentiated gravity residuals at the sampling rate originally provided by the instrument at $1 \mathrm{~s}$ or $10 \mathrm{~s}$. Table 2 includes the standard deviations for all stations. Figure 3 shows an example of three days uncorrected data of the gPhone and Burris in Hannover. Due to its location the gPhone data in Figure 3a is dominated by kinematic accelerations caused by natural and man made microseism. In addition, a filtered version is contained in the plot in grey. For the complete time series the standard deviation of the gravity residuals is $730.9 \mathrm{~nm} / \mathrm{s}^{2}$. The Burris is less affected by the microseismic characteristics of the station. The residuals of the data recorded at a $1 \mathrm{~s}$ interval (Figure 3b) using the handheld computer has a standard deviation of $16.3 \mathrm{~nm} / \mathrm{s}^{2}$. Comparing this dataset with the gPhone data shows the effect of the analog lowpass filter 


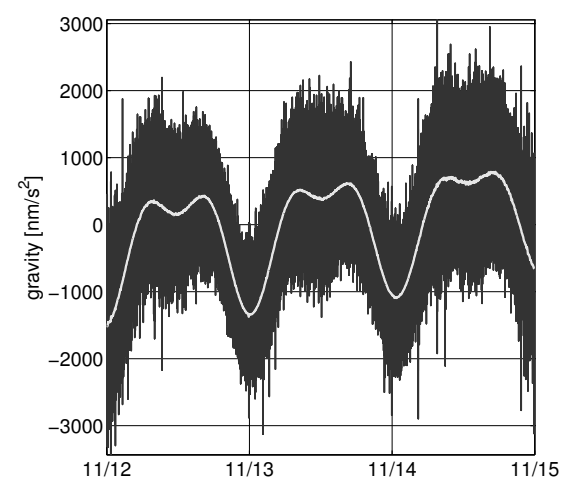

(a) gPhone $1 \mathrm{~s}$ raw data (black) and $600 \mathrm{~s}$ filtered data (grey)



(b) Burris 1s raw data recorded with handheld computer

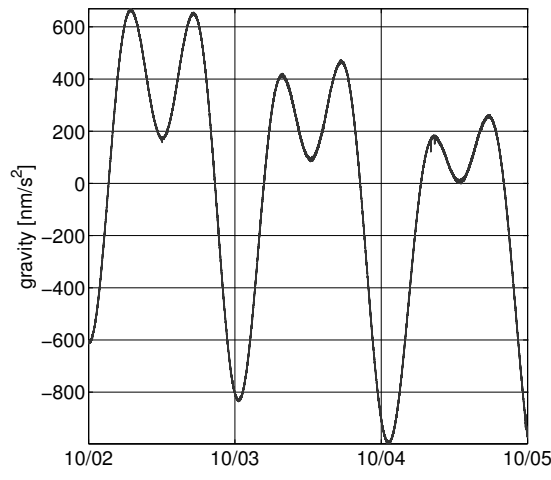

(c) Burris $10 \mathrm{~s}$ raw data recorded with FSUGrav

Figure 3: Examples of raw data from gPhone- 98 and Burris B-64 gravimeters for the length of 3 days in Hannover

built into the Burris. The gPhone on the other hand does not apply any filtering, which allows the study of high frequency signals. Except for this example the FSUGrav software with a fixed $10 \mathrm{~s}$ sampling interval and $600 \mathrm{~s}$ digital filter is used (Figure 3c). The gravity residuals of this time series have a standard deviation of $3.7 \mathrm{~nm} / \mathrm{s}^{2}$. The Burris gravimeter achieves the same standard deviations of $\approx 4 \mathrm{~nm} / \mathrm{s}^{2}$ for the $10 \mathrm{~s}$ data at all stations visited. This is probably due to the filtering performed by the FSUGrav software. The standard deviations of the gPhone data is clearly dependent on the station and its environment as well as seasonal effects allowing further investigations of station characteristics and the study of a variety of higher frequency signals. Comparing all stations within this work, Hannover has the highest influence due to man made microseismic activity. The station with the lowest noise level is Clausthal in the Harz mountains.

For all following comparisons we use gravity recordings resampled to a 300 s interval using the DECIMATE program of the ETERNA 3.4 package (Wenzel, 1996). The Burris recorded simultaneously with an instrument of higher accuracy, a superconducting gravimeter (precision of a few tenths of a nm/ $\mathrm{s}^{2}$ and drift of a few tens of $\mathrm{nm} / \mathrm{s}^{2}$ per year) in Onsala for a period of three months. Preprocessed $10 \mathrm{~s}$ data of the GWR OSG-054 was provided by Hans-Georg Scherneck (OSO). Figure 4a shows the Fourier spectrum of the Burris observations corrected using the synthetic tidal parameters (black graph) and the Fourier spectrum of the difference between Burris and OSG observations (grey graph). Using the synthetic tidal parameters, the residual amplitudes are $0.8-0.9 \mathrm{~nm} / \mathrm{s}^{2}$ for diurnal and semi-diurnal frequencies. As the Onsala sta- tion is located directly at the coast, these differences to the synthetic tidal parameters are to be expected. The difference of the observations of the two instruments exclude all environmental effects. Instrumental effects, e. g. uncertainties in the calibration, are still included. The spectrum, plotted in grey, shows the remaining periodic signals at semi- and ter-diurnal frequencies with amplitudes below $0.22 \mathrm{~nm} / \mathrm{s}^{2}$. This suggests, that the Burris is capable of recording diurnal, semi-diurnal and maybe even ter-diurnal tidal waves, given a long enough time series.

A direct comparison of gPhone and Burris is possible for the stations Hannover and Ruthe. Figure $4 \mathrm{~b}$ presents the spectra of the gPhone and Burris gravity residuals from recordings in Hannover. For higher frequencies the average noise is at the level of $0.15 \mathrm{~nm} / \mathrm{s}^{2}$ for the gPhone residuals, one order of magnitude above the Burris. Both instruments display a peak in the spectrum at semi-diurnal frequency of $0.95 \mathrm{~nm} / \mathrm{s}^{2}$. The amplitude of the gPhone residual is $0.25 \mathrm{~nm} / \mathrm{s}^{2}$ lower. At the diurnal waveband the gPhone residuals show noise at the level of $0.7 \mathrm{~nm} / \mathrm{s}^{2}$ with no distinct peak but a number of peaks from 0.7 to $1.5 \mathrm{cpd}$. The Burris, however, has a more prominent diurnal effect left in the residuals at the order of $0.5 \mathrm{~nm} / \mathrm{s}^{2}$. Due to the location of the gravimetry laboratory this is not necessarily caused by the synthetic tidal model but is induced by the environment. Figure $4 \mathrm{c}$ shows the comparison for the simultaneous recordings in Ruthe. Located outside of populated areas measurements in Ruthe are less affected by human activities, which is also reflected in the standard deviations in Table 2. The first obvious difference, when compared to Figure $4 \mathrm{~b}$, is the lower noise level of the gPhone residuals at 


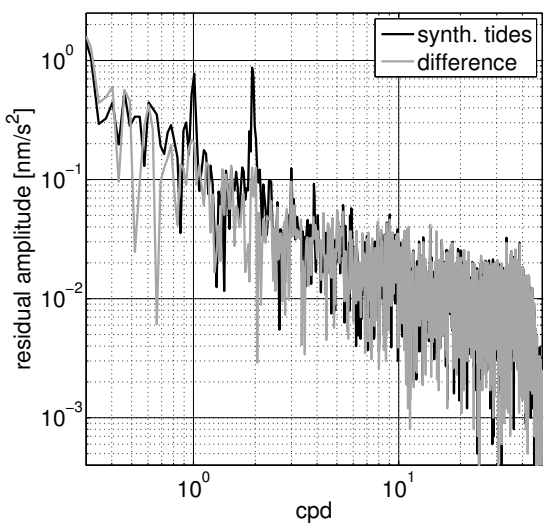

(a) Onsala: Burris data corrected with synth. tidal parameters and difference of observations of Burris and OSG

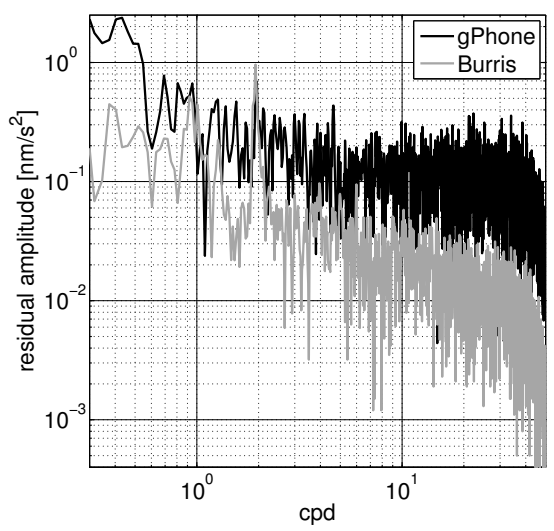

(b) Hannover: observations corrected with synthetic tidal parameters

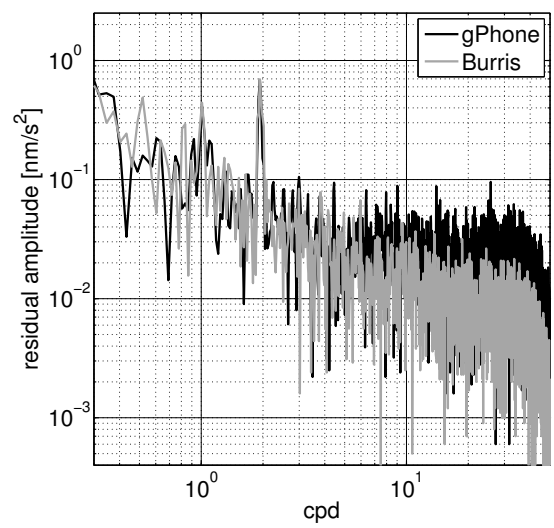

(c) Ruthe: simultaneous recordings corrected with synthetic tidal parameters

Figure 4: Fourier spectra of Burris and gPhone gravity residuals at different stations are displayed up to $50 \mathrm{cpd}$ to emphasize the lower frequencies

$3 \times 10^{-2} \mathrm{~nm} / \mathrm{s}^{2}$. In the tidal waveband periodic effects remain with an amplitude of $0.4 \mathrm{~nm} / \mathrm{s}^{2}$ and $0.7 \mathrm{~nm} / \mathrm{s}^{2}$ for the diurnal and semi-diurnal frequencies, with only slightly lower residuals for the gPhone. For the Burris instrument the spectrum for the higher frequencies does not change, which is also suggested by Table 2. The $\sigma$ of the Burris is unchanged for all stations and the gPhone shows variations of up to factor 5 for the $1 \mathrm{~Hz}$ data. Only in Clausthal the noise level of the gPhone residuals at higher frequencies is $1.5 \times 10^{-2} \mathrm{~nm} / \mathrm{s}^{2}$, which is at the same level as the Burris achieves at all stations.

\section{Tidal analysis}

Tidal parameters were calculated for the stations Hamburg, Clausthal, Onsala, and Ruthe. The tidal analysis was performed with ETERNA 3.4 using $300 \mathrm{~s}$ data. It should be noted, that the gPhone time series are usually 3 months in length, whereas the Burris observations only have 1.5 months of uninterrupted recordings. To ensure a reduction uncertainty of $1 \mathrm{~nm} / \mathrm{s}^{2}$ the tidal parameters should be obtained with accuracy of $1 \%$ of the amplitude factor and $0.05^{\circ}$ for phase lag.

For Ruthe a tidal analysis was conducted on the observations of both instruments and the results for selected tidal waves are listed in the left of Table 3. For gPhone tidal parameters for the entire length of the time series are listed as well as for the same time the Burris observations were taken. The parameters differ by less than $0.4 \%$ of the amplitude and $0.05^{\circ}$ in phase of diurnal and semidiurnal wave groups. M3 differs by $1.3 \%$ and $0.65^{\circ}$. The difference between gPhone-98 and Burris B-64 is up to $4.2 \%$ in amplitude for groups up to $\mathrm{S} 2$. The difference of the phase lag is up to $0.05^{\circ}$ for these groups. The standard deviations $\sigma$ of amplitude as well as phase of the gPhone tidal parameters are at the same level reported by Riccardi et al. (2011) up to the M2 wave. M3 is not well observed compared to the other wave groups. The shorter observation time of the Burris is reflected in its standard deviations. The mean standard deviation $\bar{\sigma}$ of the O1-S2 groups are twice as much as the $\bar{\sigma}$ of the 66 day gPhone time series parameters.

In the right part of Table 3 the results of the tidal analysis for the measurements in Onsala are shown. The data of the OSG was processed analog to the Burris data and tidal parameters are estimated from a time series of equal length. A comparison of the tidal analysis for Onsala and Ruthe from Burris data shows significantly lower standard deviations for $\mathrm{O} 1$ and $\mathrm{K} 1$ in Onsala. The semidiurnal waves M2 and S2 have slightly larger standard deviations. The parameters calculated from Burris observations differ by $0.2-0.4 \%$ in amplitude and up to $0.05^{\circ}$ in phase from the OSG except for $\mathrm{S} 2$, where the deviation is $1.7 \%$ and $0.06^{\circ}$. The semi-diurnal waves might be affected by a combination of tidal and non-tidal sea level variations of the Kattegat. These variations typically range from $10-20 \mathrm{~cm}$ in 12 hours, but weather conditions might cause a shift of the mean sea level over 
Table 3: Tidal parameters (amplitude factor and phase lag) for selected wave groups estimated from simultaneous gPhone/Burris observations in Ruthe and OSG/Burris observations in Onsala. $\bar{\sigma}$ is the mean standard deviation of the displayed groups $\mathrm{O} 1$ to $\mathrm{S} 2$.

\begin{tabular}{|c|c|c|c|c|c|c|c|c|c|c|}
\hline \multirow[b]{2}{*}{$\begin{array}{l}\text { wave } \\
\text { group }\end{array}$} & \multicolumn{6}{|c|}{ Ruthe } & \multicolumn{4}{|c|}{ Onsala } \\
\hline & $\begin{array}{l}\text { gPhone (15 } \\
\text { amplitude }\end{array}$ & $\begin{array}{l}2 \text { days) } \\
\text { phase }\left[{ }^{\circ}\right]\end{array}$ & $\begin{array}{l}\text { gPhone (66 } \\
\text { amplitude }\end{array}$ & $\begin{array}{l}\text { days) } \\
\text { phase }\left[{ }^{\circ}\right]\end{array}$ & $\begin{array}{l}\text { Burris (66 } \\
\text { amplitude }\end{array}$ & $\begin{array}{l}\text { ays) } \\
\text { phase }\left[{ }^{\circ}\right]\end{array}$ & $\begin{array}{l}\text { OSG-054 } \\
\text { amplitude }\end{array}$ & $\begin{array}{l}7 \text { days) } \\
\text { phase }\left[{ }^{\circ}\right]\end{array}$ & $\begin{array}{l}\text { Burris (97 } \\
\text { amplitude }\end{array}$ & $\begin{array}{l}\text { ays) } \\
\text { phase }\left[{ }^{\circ}\right]\end{array}$ \\
\hline $\mathrm{O} 1$ & $\begin{array}{r}1.14791 \\
\pm 0.00027\end{array}$ & $\begin{array}{r}0.1239 \\
\pm 0.0135\end{array}$ & $\begin{array}{r}1.14804 \\
\pm 0.00041\end{array}$ & $\begin{array}{r}0.0949 \\
\pm 0.0207\end{array}$ & $\begin{array}{r}1.14970 \\
\pm 0.00133\end{array}$ & $\begin{array}{r}0.1823 \\
\pm 0.0663\end{array}$ & $\begin{array}{r}1.14747 \\
\pm 0.00046\end{array}$ & $\begin{array}{r}0.1220 \\
\pm 0.0232\end{array}$ & $\begin{array}{r}1.14722 \\
\pm 0.00061\end{array}$ & $\begin{array}{r}0.1580 \\
\pm 0.0307\end{array}$ \\
\hline K1 & $\begin{array}{r}1.13524 \\
\pm 0.00020\end{array}$ & $\begin{array}{r}0.2511 \\
\pm 0.0102\end{array}$ & $\begin{array}{r}1.13486 \\
\pm 0.00040\end{array}$ & $\begin{array}{r}0.2654 \\
\pm 0.0203\end{array}$ & $\begin{array}{r}1.13955 \\
\pm 0.00133\end{array}$ & $\begin{array}{r}0.2735 \\
\pm 0.0660\end{array}$ & $\begin{array}{r}1.13910 \\
\pm 0.00046\end{array}$ & $\begin{array}{r}0.1249 \\
\pm 0.0232\end{array}$ & $\begin{array}{r}1.13874 \\
\pm 0.00059\end{array}$ & $\begin{array}{r}0.1234 \\
\pm 0.0295\end{array}$ \\
\hline M2 & $\begin{array}{r}1.18411 \\
\pm 0.00026\end{array}$ & $\begin{array}{r}1.6932 \\
\pm 0.0125\end{array}$ & $\begin{array}{r}1.18433 \\
\pm 0.00036\end{array}$ & $\begin{array}{r}1.6459 \\
\pm 0.0175\end{array}$ & $\begin{array}{r}1.18626 \\
\pm 0.00043\end{array}$ & $\begin{array}{r}1.6891 \\
\pm 0.0206\end{array}$ & $\begin{array}{r}1.18722 \\
\pm 0.00032\end{array}$ & $\begin{array}{r}1.2148 \\
\pm 0.0152\end{array}$ & $\begin{array}{r}1.18703 \\
\pm 0.00056\end{array}$ & $\begin{array}{r}1.2653 \\
\pm 0.0271\end{array}$ \\
\hline S2 & $\begin{array}{r}1.18374 \\
\pm 0.00061\end{array}$ & $\begin{array}{r}0.3918 \\
\pm 0.0296\end{array}$ & $\begin{array}{r}1.18363 \\
\pm 0.00112\end{array}$ & $\begin{array}{r}0.3751 \\
\pm 0.0550\end{array}$ & $\begin{array}{r}1.18877 \\
\pm 0.00136\end{array}$ & $\begin{array}{r}0.3875 \\
\pm 0.0668\end{array}$ & $\begin{array}{r}1.17845 \\
\pm 0.00096\end{array}$ & $\begin{array}{r}0.2812 \\
\pm 0.0461\end{array}$ & $\begin{array}{r}1.18049 \\
\pm 0.00165\end{array}$ & $\begin{array}{r}0.3444 \\
\pm 0.0789\end{array}$ \\
\hline M3 & $\begin{array}{r}1.05415 \\
\pm 0.00848\end{array}$ & $\begin{array}{r}0.4651 \\
\pm 0.4610\end{array}$ & $\begin{array}{r}1.05275 \\
\pm 0.01236\end{array}$ & $\begin{array}{r}1.1120 \\
\pm 0.6724\end{array}$ & $\begin{array}{r}1.09265 \\
\pm 0.02490\end{array}$ & $\begin{array}{r}-0.9849 \\
\pm 1.3043\end{array}$ & $\begin{array}{r}1.05960 \\
\pm 0.00711\end{array}$ & $\begin{array}{r}1.4674 \\
\pm 0.3842\end{array}$ & $\begin{array}{r}1.05551 \\
\pm 0.02126\end{array}$ & $\begin{array}{r}0.4487 \\
\pm 1.1545\end{array}$ \\
\hline $\bar{\sigma}$ & \pm 0.00034 & \pm 0.0165 & \pm 0.00057 & \pm 0.0284 & \pm 0.00111 & \pm 0.0549 & \pm 0.00055 & \pm 0.0269 & \pm 0.00085 & \pm 0.0416 \\
\hline
\end{tabular}

Table 4: Residual amplitudes in $\mathrm{nm} / \mathrm{s}^{2}$ at 1 and 2 cycles per day from synthetic and observed tidal parameters.



a period of several days. Olsson et al. (2009) describe the effect of sea surface tilt of the Baltic Sea and calculated the gravitational effect to be $6-9 \mathrm{~nm} / \mathrm{s}^{2}$ for Onsala in two case studies. Mammadov et al. (2011) report on a tidal recording using the Burris B-14 gravimeter for the period of one year in Shaki, Azerbaijan reaching slightly higher standard deviations than the B-64 in Onsala.

Due to the proximity of the station in Hamburg to Elbe and North Sea the residuals, after correcting the observations with the synthetic tidal model, still show a periodic effect with $2 \mathrm{cpd}$ and an amplitude of $1.4 \mathrm{~nm} / \mathrm{s}^{2}$. Table 4 summarizes the residual amplitudes at 1 and $2 \mathrm{cpd}$ for all stations. Correcting the observations with the tidal parameters estimated in the tidal analysis removes this peak altogether. At $1 \mathrm{cpd}$ the remaining residual is at the noise level. In Clausthal the observed parameters reduce the residuals at diurnal and semi-diurnal frequencies by the factor of about 3.6. The recordings performed at both stations resulted in improved tidal parameters for the gPhone-98. To verify these parameters additional measurements, preferably with a different instrument, are to be taken.

\section{Summary}

Gravity was recorded with the IfE gravimeters Micro-g LaCoste gPhone-98 and ZLS Burris Gravity Meter B64 in Hamburg, Hannover, Ruthe, Clausthal and Onsala to determine the tidal parameters and to assess the accuracy of the instruments. The linear calibration factor for both instruments was determined repeatedly and found to be stable to $3 \times 10^{-4}$. The drift of the gPhone has decreased with the age of the instrument and is currently at $\approx 90 \mathrm{~nm} / \mathrm{s}^{2}$ per day after a period of 2 weeks at a new station. The Burris currently shows a non-linear drift with high variations within a few weeks. Using the stepresponse method a phase delay of 3 seconds is estimated for the Burris. Testing the Burris in a pressure chamber revealed an instrumental air pressure coefficient of $0.14 \mathrm{~nm} / \mathrm{s}^{2}$ per $\mathrm{hPa}$. The adjustment of a gravity network using hand transport from Burris measurements resulted in a mean standard deviation of $10 \mathrm{~nm} / \mathrm{s}^{2}$ of the adjusted gravity values.

The tidal analysis of gPhone-98 recordings in Clausthal and Hamburg resulted in improved tidal parameters for these stations. Especially for Hamburg the im- 
provement is noticeable due to the effect of ocean tides, which are not well estimated by the synthetic tidal model close to the coast. In Ruthe the tidal analysis of both instruments provided mixed results. The gPhone amplitude factors for diurnal and semi-diurnal groups show a mean standard deviation of $0.3 \times 10^{-3}$ for a time series of 152 days and of $0.6 \times 10^{-3}$ for a shorter period of 66 days. For the Burris, with an observation time of 66 days, the mean standard deviation is $2-3$ times higher when compared to the 66 and 152 day long time series of gPhone. The diurnal and semi-diurnal tidal amplitude factors from both instruments agree to $1.5-4.2 \%$. The tidal analysis of the Burris measurements in Onsala resulted in parameters for $\mathrm{O} 1, \mathrm{~K} 1$ and $\mathrm{M} 2$ which agree to $0.3 \%$ and $\mathrm{S} 2$ to $1.7 \%$ with the parameters derived from GWR OSG-054 data of the same time span and processed the same way. Burris B-64 and gPhone-98 gravimeters show satisfactory results better than $1 \%$ o for the amplitude factors and $0.05^{\circ}$ for phase lags obtained from the observations of diurnal and semi-diurnal tidal waves. However, the gPhone achieves a lower mean standard deviation of these parameters in a shorter observation time at one station that was occupied with Burris and gPhone at the same time.

\section{Acknowledgements}

This work was in part funded by the German Research Foundation (DFG, MU 1141/16-1). The Centre for Quantum Engineering and Space-Time-Research (QUEST) provided funding for the gPhone-98. The authors thank Hans-Georg Scherneck and the Onsala Space Observatory for hosting our instrument and providing gravity and environmental data, and the Leibniz Institute for Applied Geophysics for the cooperation in Hamburg.

\section{References}

Jentzsch, G. (2008). "The automated Burris gravity meter-a new instrument using an old principle". In: Proc Symposium on Terrestrial Gravimetry Static and Mobile Measurements St Petersburg Russia, pp. 20-23 (cit. on p. 3).

Jiang, Z., V. Pálinkáš, O. Francis, P. Jousset, J. Mäkinen, S. Merlet, M. Becker, A. Coulomb, K. U. KesslerSchulz, H. R. Schulz, C. Rothleitner, L. Tisserand, and D. Lequin (2012). "Relative gravity measurement campaign during the 8th International Comparison of Absolute Gravimeters (2009)". In: Metrolo- gia 49.1, pp. 95-107. DOI: 10.1088/0026-1394/ 49/1/014 (cit. on p. 4).

LaCoste \& Romberg (2004). Instruction manual Model $G$ and $D$ gravity meters. Austin, Tx, USA: LaCoste \& Romberg (cit. on p.2).

Mammadov, S., T. Jahr, G. Jentzsch, and F. Kadirov (2011). "Primary results of new gravity station Shaki/Azerbaijan". In: Bull. d'Inf. Marées Terrest. 147, pp. 11881-11890 (cit. on p. 7).

Micro-g LaCoste (2008). gPhone/P.E.T Hardware Manuel V1. Lafayette, Co, USA: Micro-g LaCoste (cit. on pp.2, 4).

Olsson, P.-A., H.-G. Scherneck, and J. Ågren (Dec. 2009). "Effects on gravity from non-tidal sea level variations in the Baltic Sea". In: Journal of Geodynamics 48.3-5, pp. 151-156. DOI: $10.1016 / \mathrm{j} \cdot \mathrm{jog}$. 2009.09 .002 (cit. on p. 7).

Riccardi, U., S. Rosat, and J. Hinderer (2011). "Comparison of the Micro-g LaCoste gPhone-054 spring gravimeter and the GWR-C026 superconducting gravimeter in Strasbourg (France) using a 300-day time series". In: Metrologia 48.1, pp. 28-39. DOI: 10 . 1088/0026-1394/48/1/003 (cit. on pp. 3, 6).

Richter, B. and H.-G. Wenzel (1991). "Precise instrumental phase lag determination by the step response method". In: Bull. d'Inf. Marées Terrest. 111, pp. 8032-8052 (cit. on p. 4).

Scherneck, H.-G. (2008). Status report to the Global Geodynamics Project: superconducting gravimeter station at the Onsala Space Observatory, The national facility for radio astronomy in Sweden. Tech. rep. Onsala Space Observatory (cit. on p. 2).

Timmen, L. and H.-G. Wenzel (1995). "Worldwide Synthetic Gravity Tide Parameters". In: Gravity and Geoid. Ed. by H. Sünkel and I. Marson. Vol. 113. International Association of Geodesy Symposia. Springer Berlin Heidelberg, pp. 92-101. DOI: 10 . 1007/978-3-642-79721-7_11 (cit. on p. 4).

Timmen, L. (2010). "Absolute and Relative Gravimetry". In: Sciences of Geodesy - I. Ed. by G. Xu. Springer Berlin Heidelberg, pp. 1-48. DOI: 10.1007/9783-642-11741-1_1 (cit. on pp. 2, 3).

Timmen, L. and O. Gitlein (2004). "The capacity of the Scintrex Autograv CG-3M no. 4492 gravimeter for "absolute-scale" surveys". In: Revista Brasileira de Cartografia 56.2, pp. 89-95 (cit. on pp.1. 4). 
Van Camp, M. and P. Vauterin (2005). "Tsoft: graphical and interactive software for the analysis of time series and Earth tides". In: Computers \& Geosciences 31.5, pp. 631-640 (cit. on p. 4).

Wenzel, H.-G. (1996). "The nanogal software: Earth tide data processing package ETERNA 3.30". In: Bull. d'Inf. Marées Terrest. 124, pp. 9425-9439 (cit. on p. 57.

ZLS Corporation (2011). User Guide: Burris Gravity Meter and UltraGrav control system. Austin, Tx, USA: ZLS Corporation (cit. on p.2). 